\title{
MENSURAÇÃO DA CAPACIDADE ABSORTIVA DE FIRMAS QUE POSSUEM INTERAÇÃO COM UNIVERSIDADES
}

\author{
Andreia Cunha da Rosa ${ }^{1}$ \\ Janaina Ruffoni ${ }^{2}$
}

\begin{abstract}
Resumo
A literatura tem destacado contribuições da interação universidade-empresa (U-E) para o desempenho inovativo da firma, uma vez que ao interagir, a firma acessa e utiliza conhecimentos externos, ampliando sua possibilidade de inovar. Um aspecto fundamental para que a interação UE resulte em inovações é a capacidade da firma de absorver o conhecimento externo. Para avançar na compreensão da relação entre interação U-E e capacidade absortiva (CA) é fundamental conhecer como a CA é mensurada. Após uma análise da literatura entre 2000 e 2012, três estudos atuais foram selecionados por apresentarem aderência à discussão aqui sugerida e elementos de mensuração já validados empiricamente. Com base nisso, foi proposta uma estrutura de mensuração, verificada empiricamente em uma pesquisa survey - realizada em 2013 com firmas que possuíam interação com universidades - e validada pelos resultados favoráveis da análise de confiabilidade realizada. O trabalho contribui ao propor um conjunto sintético de elementos de mensuração da capacidade absortiva já ${ }^{a}$ validados empiricamente e aponta para avanços necessários em direção à uma proposta mais específica à realidade de firmas que interagem com universidades e à inclusão das dimensões da capacidade absortiva científica e industrial na análise da dinâmica inovativa de firmas que interagem com universidades.
\end{abstract}

Palavras chave: Capacidade de Absorção da Firma; Interação Universidade-Empresa; Mensuração.

\begin{abstract}
The literature has highlighted contributions of university-enterprises interaction (UE) for the firm's innovative performance, since when interacting the firm access and use external knowledge, expanding their ability to innovate. A key aspect for UE interaction results in innovations is the firm's ability of the firm to absorb external knowledge. To advance in understanding the relationship between UE interaction and absorptive capacity (AC) is essential to understand how CA is measured. After a review of the literature between 2000 and 2012, three current studies were selected because of their adherence to the proposal discussion here and suggested measurement elements already empirically validated. Based on this, a framework for measuring was proposed, verified empirically in a survey research - held in 2013 with firms that had interaction with universities - and validated by the reliability analysis favorable results. The paper contributes by proposing a synthetic set of measuring absorptive capacity elements already validated empirically and points to progress towards a more specific proposal to the reality of firms that interact with universities and to include in the measures other two dimensions of firm's absorptive capacity: the scientific and industrial.

Keywords: Firm’s Absorptive Capacity; University-Industry Interactions; Measure.

1 Mestre pelo PPGE-UNISINOS. E-mail: andreiacr2@yahoo.com.br

${ }^{2}$ Graduada em Ciências Econômicas pela FCE/UFRGS, mestre em Gestão de Ciência e Tecnologia pelo PPGA/UFRGS e doutora em Política Científica e Tecnológica pelo DPCT/UNICAMP. Professora do Programa de Pós-Graduação em Economia da UNISINOS. Coordena o Grupo de Pesquisa em Dinâmica Econômica da Inovação (GDIN). E-mail: janainart@ gmail.com
\end{abstract}

Recebido em: 17/02/2014

Aceito em: 27/03/2014 


\section{INTRODUÇÃO}

As firmas são cada vez mais afetadas pelo acirramento da competição. Com novos campos de conhecimento em rápida evolução, os ciclos de vida dos produtos e processos se tornam cada vez mais curtos. Para sobreviver, as firmas precisam introduzir novos bens e serviços e encontrar novas formas de fazer negócios, o que exige que desenvolvam constantemente capacidades para inovar.

Alguns estudos têm reconhecido que uma mesma inovação, quando introduzida em diferentes firmas, gera resultados diversos dependendo do contexto no qual é inserida e das intervenções que sofre na implementação (Barley, 1986; Orlikowski, 1993; Robey e Sahay, 1996; Markus e Robey, 1988; Ciborra, 2000 apud Cullar e Gallivan, 2006). Conforme Spender (1989), diferenças na trajetória das firmas e nos recursos que possuem, particularmente o conhecimento, leva cada uma a desenvolver um conjunto específico de capacidades.

Uma importante capacidade da firma foi destacada por Cohen e Levinthal (1990). Esses autores introduziram o conceito de capacidade de absorção, explicando que quando uma empresa deseja adquirir e usar conhecimentos que não estão relacionados com sua base de conhecimento atual, esforços deliberados são necessários para criar capacidade de absorção. Essa capacidade diz respeito principalmente à habilidade de uma organização para obter (novo) conhecimento e usá-lo para estimular as suas atividades de inovação como uma resposta ativa a um mercado em constante mudança. Quanto maior for a capacidade de absorção de uma empresa, maior será a capacidade desta acessar e implementar uma maior quantidade de conhecimentos (Negassi, 2004; Schmidt, 2005).

No que diz respeito à obtenção de conhecimento externo pelas firmas, a literatura acadêmica destaca importantes contribuições da interação entre universidade e empresa (UE), ao permitir que as firmas consigam, por meio da troca de conhecimentos com o meio acadêmico, incrementar seus desempenhos inovativos (Link e Rees, 1990; Mansfield, 1991; George e Zahra et al., 2002; Laursen e Salter, 2004; Póvoa, 2008). Por interação universidade-empresa entende-se um arranjo interinstitucional entre organizações de natureza distinta, que podem ter finalidades diversas e adotar formatos bastante diferentes. Incluem-se nesse conceito desde interações que objetivam algo pontual, como, por exemplo, estágios profissionalizantes, até vinculações mais intensas entre os dois atores, como grandes programas de pesquisa básica e aplicada cooperativa, podendo resultar na divisão dos créditos adquiridos com a comercialização dos resultados da pesquisa (Plonski ,1999). 
O conhecimento novo gerado pela pesquisa universitária pode proporcionar avanços importantes para as firmas com potencial de comercialização no longo prazo (Nelson e Rosenberg, 1993). Entretanto, a sua transferência implica fluxos de informação e de tecnologia que exigem capacidade de absorção por parte do receptor (Povoa e Rapini, 2009).

A capacidade das empresas para aproveitar o conhecimento gerado externamente tem um efeito positivo sobre o sucesso nas inovações e está associada com a decisão de realizar a pesquisa em colaboração com outras instituições (Abramovsky et al., 2008). Com isso, a capacidade de uma firma para absorver conhecimentos do ambiente externo (como os gerados em Universidades) e usá-los no desenvolvimento de inovações, já referida como a capacidade de absorção, tornou-se uma importante questão em estudos econômicos (Waalkens, 2006).

$\mathrm{O}$ interesse acadêmico pela capacidade de absorção (CA) das empresas tem crescido desde os estudos Cohen e Levinthal (1989, 1990 e 1994), e está focado nos efeitos da capacidade absortiva sobre o aprendizado da firma, o compartilhamento de conhecimento, a geração de inovação, o desenvolvimento de capacidade e o desempenho competitivo. Entretanto, percebe-se uma carência de métricas capazes de medir a CA de firmas que utilizam as Universidades como fonte de conhecimento externo.

Assim, objetiva-se neste trabalho identificar indicadores que traduzem o conceito de CA e propor uma estrutura passível de ser utilizada em pesquisas empíricas. Para o alcance dos objetivos propostos foi realizada uma revisão da literatura a partir de uma pesquisa bibliográfica em diferentes bases de dados para o período de 2000 a 2012. Procedeu-se, então, à análise da contribuição específica de artigos que tratam da aplicação do conceito de CA e à verificação das proposições de métricas validadas empiricamente, conforme descrito na terceira seção deste artigo.

O trabalho está organizado em cinco partes, incluindo essa introdução. Na segunda apresenta-se a base conceitual sobre capacidade absortiva. Na terceira parte apresenta-se os indicadores de mensuração da capacidade absortiva encontrados na revisão da literatura. $\mathrm{Na}$ quarta é construída uma proposta de estrutura de mensuração desta capacidade para empresas que possuem interações com Universidade. Por fim, são feitas as considerações finais

\section{CONCEITUAÇÃO DE CAPACIDADE ABSORTIVA}

Cohen e Levinthal (1990) definem capacidade de absorção como a capacidade de uma firma de reconhecer o valor do novo conhecimento externo, assimilá-lo e aplicá-lo para fins comerciais. Esses mesmos autores, consideram que a inovação é gerada por meio do processo 
de aprendizado da firma (dependente de trajetória) e que a capacidade de absorção é constituída a partir de um conjunto de conhecimentos prévios. Os autores argumentam que a capacidade de avaliar e utilizar o conhecimento externo é em grande parte função do nível de conhecimento prévio. No nível mais elementar, este conhecimento prévio inclui habilidades básicas ou até mesmo uma linguagem comum, mas pode também incluir o conhecimento dos mais recentes desenvolvimentos científicos ou tecnológicos de uma determinada área. Cohen e Levinthal (1990) sugerem que empresas com níveis mais elevados de capacidade absortiva tendem a ser mais proativas e capazes de explorar oportunidades presentes no ambiente. Desta forma, a relação entre o aprendizado da firma e a capacidade absortiva é o ponto central dos estudos elaborados por Cohen e Levinthal (1989, 1990), no qual a capacidade absortiva leva a um maior aprendizado, aumentando a base de conhecimento, que por sua vez, aumenta a capacidade absortiva e, com isso, leva a um maior potencial de aprendizado. Eles argumentaram que, se os custos de aquisição de conhecimentos externos são pequenos no momento da aprendizagem, é porque a empresa já investiu no desenvolvimento da capacidade de identificar, assimilar e explorar o conhecimento externo, o que é chamado de aprendizagem da firma ou capacidade de absorção (Cohen e Levinthal 1989, 569).

Cohen e Levinthal (1990) estabelecem três dimensões, que derivam do conceito de capacidade absortiva. A primeira é a habilidade da firma de reconhecer o valor do novo conhecimento externo. Para permitir a utilização efetiva e criativa do novo conhecimento adquirido, a firma deve possuir um nível de conhecimento prévio que facilite o reconhecimento do valor do conhecimento externo. A segunda dimensão é a capacidade da firma de assimilar o novo conhecimento, internalizando-o. Por último, a terceira diz respeito à capacidade de comercializar o novo conhecimento; quanto mais experiência as organizações envolvidas tiverem na resolução de problemas semelhantes, mais fácil será para a empresa receptora encontrar uma aplicação comercial para o conhecimento recentemente assimilado.

A definição original de capacidade absortiva elaborada por Cohen e Levinthal (1989, 1990) destaca, portanto, três dimensões, mas várias re-conceituações têm surgido na literatura (por exemplo, Jansen et al., 2005; Torodova \& Durisin, 2007; Van Den Bosch et al., 2003; Zahra \& George, 2002), pois havia o entendimento de que o conceito estava sendo utilizado mais como uma retórica do que como uma dimensão investigativa (Versiani et al., 2010). Camisón \& Forés (2010) destacam que as contribuições mais significativas na discussão da aplicação do conceito são as de Mowery e Oxley (1995), Kim (1998), Lane e Lubatkin 
(1998), Dyer e Singh (1998), Van den Bosch et al. (1999), Zahra e George (2002) e Lane et al. (2006).

O aprofundamento do conceito de capacidade absortiva veio a ocorrer aproximadamente uma década após o seu surgimento, a partir da discussão feita por Zahra e George (2002), os quais apresentam uma distinção entre capacidade absortiva potencial e realizada. A capacidade absortiva potencial permite a firma ser receptiva ao conhecimento externo, isto é, adquirir, analisar, interpretar e compreender este conhecimento, envolvendo as dimensões de aquisição e assimilação. Os autores mencionam que o simples fato de uma firma adquirir e avaliar o conhecimento externo não garante que ela consiga explorá-lo, pois isso, conforme Cohen e Levinthal (1990), depende da capacidade técnica da firma. Mencionam que quanto maior for esta capacidade, maior conseguirá compreender e assimilar o conhecimento externo e usufruir dos benefícios obtidos a partir desse conhecimento. Zahra e George (2002) mencionam que a capacidade absortiva realizada reflete a capacidade da firma em transformar e explorar o novo conhecimento, incorporando-o ao conhecimento prévio. Esta capacidade é determinada pelas dimensões de transformação e de exploração. Os autores definem as quatro dimensões de capacidade absortiva da seguinte forma:

- a aquisição refere-se à capacidade de identificar e obter conhecimentos de fontes externas (por exemplo, fornecedores, Universidades, clientes, entre outros);

- a assimilação diz respeito à capacidade de uma empresa de desenvolver processos e rotinas úteis na análise, interpretação e compreensão dos conhecimentos adquiridos externamente;

- a transformação significa desenvolver e aperfeiçoar as rotinas que facilitam a combinação de conhecimento existente com o conhecimento adquirido e assimilado para uso posterior; e

- a exploração denota a capacidade para melhorar, expandir e utilizar suas rotinas existentes, competências e tecnologias para criar algo novo com base no conhecimento transformado.

Dentre as contribuições mais recentes, destaca-se a de Jiménez-Barrionuevo et al. (2011), no qual, a partir das definições de Zahra e George (2002) e de uma exaustiva revisão bibliográfica definem as quatro dimensões da capacidade absortiva como segue:

- capacidade de aquisição: localizar, identificar, avaliar e adquirir conhecimento externo que é importante para o desenvolvimento de suas operações (por exemplo, Lane e Lubatkin, 1998; Zahra e George, 2002); 
- capacidade de assimilação: analisar, classificar, processar, interpretar e, finalmente, internalizar e compreender o conhecimento externo (por exemplo, Cohen e Levinthal, 1990; Szulanski, 1996);

- capacidade de transformação: facilitar a transferência e combinação de conhecimento prévio com o conhecimento recém-adquirido ou assimilado; consiste em adicionar ou eliminar conhecimentos e de interpretar e combinar outros conhecimentos existentes de nova e distinta maneira (por exemplo, Jansen et al., 2005; Todorova e Durisin, 2007); e

- capacidade de exploração: incorporar o conhecimento adquirido, assimilado e transformado nas operações e rotinas para a aplicação e uso; esta capacidade vai originar a criação ou melhoria de novos produtos, sistemas, processos, formas de organização e competências (por exemplo, Lane et al., 2001; Zahra e George, 2002).

Tendo em vista as principais contribuições dos pesquisadores analisados por JiménezBarrionuevo et al. (2011, p.192), esses autores definem a capacidade de absorção como a “capacidade relativa da organização para desenvolver um conjunto de rotinas organizacionais e processos estratégicos através do qual se adquire, assimila, transforma e explora os conhecimentos adquiridos externamente a fim de criar valor". Esta nova definição leva em conta as quatro fases do desenvolvimento da capacidade de absorção considerada por Zahra e George (2002).

Tsai (2001) e Makhija e Ganesh (1997) apud Chen (2004) compartilham das idéias de Cohen e Levinthal $(1989,1990)$ e argumentam que as empresas com um alto nível de capacidade de absorção são mais susceptíveis a ter uma melhor compreensão e aproveitamento dos novos conhecimentos gerados em outras organizações. Portanto, o desenvolvimento persistente da capacidade da firma de absorver conhecimentos é uma condição necessária para a exploração bem sucedida de conhecimentos externos. Desta forma, ao se investigar firmas que possuem interação com universidades para a geração de inovações tem-se como hipótese que essa empresas possuem elevada capacidade de absorção, pois buscam e utilizam conhecimento externo. Também entende-se que o nível de CA da firma está relacionado com o período de existência da prática da interação, ou seja, quanto mais tempo a firma realiza interações com universidades, e assim rotiniza a utilização de conhecimento externo, mais elevada deve ser a sua capacidade absortiva.

Vega-Jurado et al. (2008, p. 395) entendem que a capacidade de absorção é determinada não só pelas atividades de pesquisa e desenvolvimento, mas também por um conjunto de fatores internos que eles classificam em três categorias básicas descritas a seguir. 
- Conhecimento Organizacional: conjunto de habilidades, conhecimentos e experiências que uma firma possui, sendo determinado pela sua base de conhecimento prévio; pela experiência acumulada na busca por novos conhecimentos, pelas habilidades individuais de seus trabalhadores e por suas atividades de P\&D.

- Formalização: proporção em que os procedimentos, regras e instruções regulam os processos internos das firmas, ou seja, reflete o grau em que os comportamentos são programados por regras formais explícitas. No entanto, [...] "um elevado nível de formalização terá uma influência negativa sobre a flexibilidade e a espontaneidade dos trabalhadores da empresa para responder em situações de crise, e tende a reduzir a contribuição criativa e desencorajar a inovação". (VEGA-JURADO et al., 2008, p. $395)$.

- Mecanismos de Integração Social ações que reduzem as barreiras à troca de informações dentro de uma firma, encorajando a interação entre os trabalhadores e facilitando a absorção de conhecimento. Essas ações são mais eficazes em atividades que requerem um nível cognitivo considerável, tais como transformação e exploração.

Segundo Vega-Jurado et al. (2008), esses fatores podem influenciar todos os componentes da capacidade de absorção da firma de forma positiva ou negativa, dependendo da aplicação do conhecimento que está sendo absorvido. Assim, os autores apresentam um modelo de análise de fatores que determinam a CA, incluindo a aplicabilidade do conhecimento disponível no ambiente como um fator determinante para moderar os efeitos dos antecedentes da CA da firma, conforme demostrado na Figura 1.

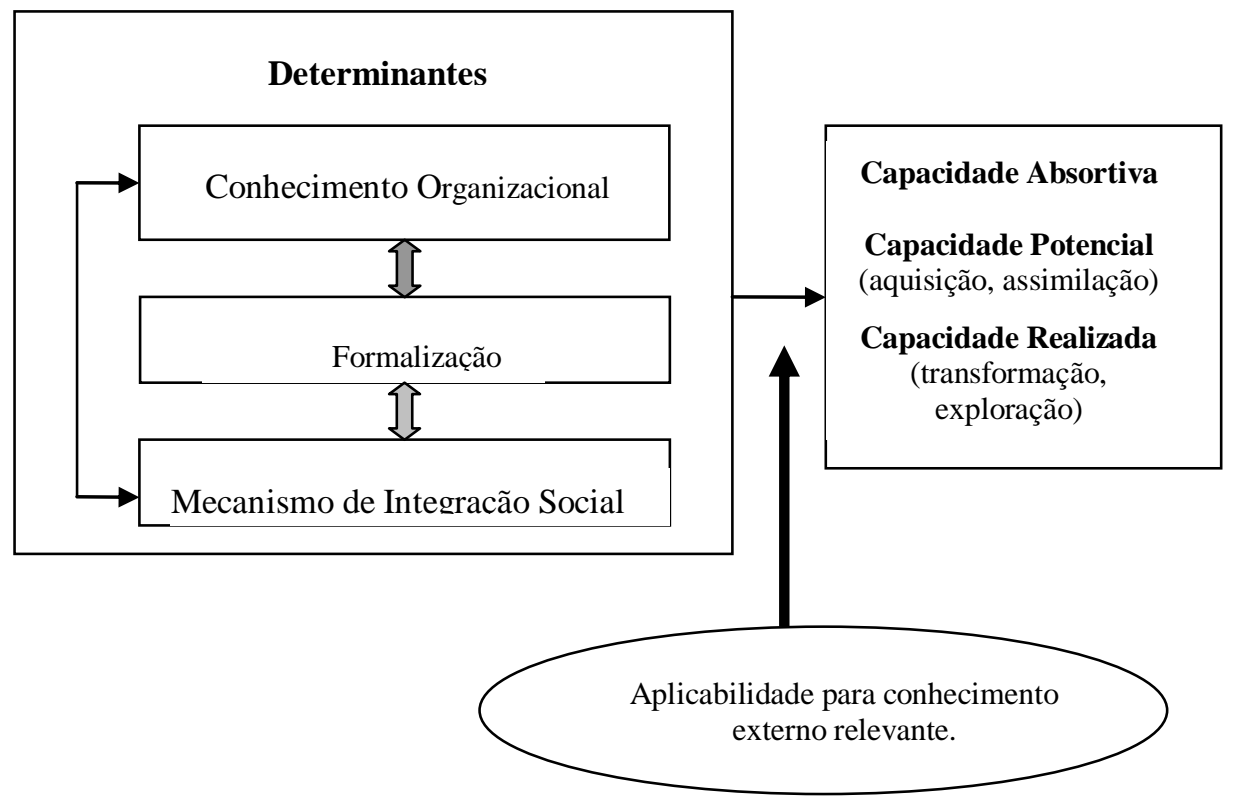

Figura 1: Modelo de Capacidade Absortiva

Fonte: traduzido e adaptado de Vega-Jurado et al. , 2008, p. 395. 
Na Figura 1, a "Aplicabilidade para conhecimento externo relevante" refere-se ao grau em que o conhecimento externo é dirigido às necessidades específicas da firma, e que estaria relacionado com o que Cohen e Levinthal (1989) denominaram de "facilidade de aprendizagem". Conforme Vega-Jurado et al. (2008), vários autores apontaram para a relevância da natureza do conhecimento externo no processo de aprendizagem da firma. Mencionam também que a CA é influenciada pelo grau de complexidade do conhecimento, sendo que conhecimentos complexos requerem interações mais fortes enquanto que para conhecimentos mais simples essa interação não é tão necessária.

Assim, os autores contribuem com a literatura apresentando dois conceitos de capacidade de absorção: a CA Científica e a CA Industrial. Conforme eles, a CA Científica refere-se à capacidade de absorver conhecimentos provenientes das universidades, institutos tecnológicos e eventos científicos. Já a CA Industrial é a capacidade de assimilar e explorar o conhecimento proveniente de parceiros industriais, como clientes, concorrentes, fornecedores, entre outros. Assim, os fatores que determinam o desenvolvimento de cada um destes dois tipos de CA são diferentes, apesar de que em certos setores podem ser complementares.

Na próxima sessão são apresentadas as principais contribuições da literatura referente às formas de mensuração da capacidade de absorção de firmas.

\section{MENSURAÇÃO DA CAPACIDADE ABSORTIVA}

$\mathrm{Na}$ revisão da literatura realizada anteriormente observou-se desenvolvimento na conceituação de CA. Para avançar na proposta do artigo, apresenta-se o que a literatura relata no que diz respeito à mensuração deste conceito.

Versiani et al. (2010) e Flatten et al. (2011) destacam que mesmo que um número considerável de estudos empíricos tenham sido realizados sobre Capacidade Absortiva, uma medida válida que incorpora suas várias dimensões ainda não foi desenvolvida. Entende-se que a dificuldade na definição de métricas ocorre como resultado de um não consenso a respeito das dimensões que compõem o conceito. A maioria dos pesquisadores optou por medir a CA considerando-a tipicamente como uma proxy de P\&D (por exemplo, Cohen e Levinthal, 1989, 1990), não incluindo assim suas várias dimensões e suas implicações para os diferentes resultados na firma. Assim, os atributos de conhecimento têm sido ignorados, apesar de sua importância ser apontada seguidamente nas literaturas sobre transferência de tecnologia e aprendizagem da firma (Veja-Jurado, 2008).

Com vistas a avançar nessas questões, realizou-se uma pesquisa bibliográfica em 
diferentes bases de dados, utilizando as palavras chaves "Absorptive Capacity", "Measure" e "Metrics" para o período compreendido entre 2000 e 2012. A partir desta revisão bibliográfica, identificaram-se importantes contribuições de estudos mais recentes. Os critérios para a escolha dos estudos definidos para a discussão das métricas de CA foram: 1) a atualidade da publicação, sendo considerados aqueles publicados nos últimos 5 anos; 2) a utilização de diferentes proxies para medir a CA nas dimensões de aquisição, assimilação, transformação e exploração desenvolvidos por Zahra e George (2002), por se entender ser essa uma explicação de largo alcance a respeito da CA da firma; e 3) a validação empírica das métricas; foram selecionados estudos que tivessem sido testados em uma base amostral significativa para que fosse possível faz uso de resultados generalizáveis.

O levantamento resultou nos artigos elaborados por Camisón e Forés (2010), em que enfatizam a mensuração multidimensional da CA; por Jiménez-Barrionuevo et al. (2011); e por Flatten et al. (2011). A seguir são apresentados os principais resultados de cada um desses trabalhos.

\subsection{Proposta de uma mensuração multidimensional}

Visando contribuir com a literatura de CA, Camisón \& Forés (2010) desenvolveram um estudo onde procuraram construir e validar empiricamente uma proposta de mensuração multi-dimencional da CA. O modelo proposto é formado por duas escalas com itens que medem a CA Potencial e Realizada. Os autores procuraram ampliar e validar empiricamente a contribuição teórica de Zara e George (2002). A partir da revisão bibliográfica, os autores procuraram identificar as rotinas, os mecanismos e as atividades que formam a CA potencial e realizada bem como as ferramentas com as quais se desenvolve as medidas do construto, a fim de justificarem os atributos selecionados para operacionalizar cada dimensão da CA. Na Tabela 1 são apresentados os elementos que caracterizam os dois tipos de CA trabalhados pelos autores e o elenco dos estudos que antecedem a sua utilização.

Tabela 1: Elementos e literatura antecedente de CA Potencial e Realizada.

\begin{tabular}{|c|c|}
\hline Elementos & Estudos antecedentes \\
\hline \multicolumn{2}{|l|}{ Capacidade Absortiva Potencial } \\
\hline \multicolumn{2}{|l|}{ Capacidade de Aquisição (AD) } \\
\hline AD1 - Conhecimento dos concorrentes & Lane et al. (2001), Nieto e Quevedo (2005), Tu et al. (2006) \\
\hline AD2 - Abertura em relação ao ambiente & $\begin{array}{l}\text { Caloghirou et al. (2004), Lane et al. (2001), Jansen et al. (2005), } \\
\text { Nieto e Quevedo (2005), Soo et al. (2007), Tu et al. (2006) }\end{array}$ \\
\hline AD3 - Pesquisa e desenvolvimento cooperativo & $\begin{array}{l}\text { Arbussà e Coenders (2007), Caloghirou et al. (2004), Jansen et al. } \\
\text { (2005), Liao et al. (2003), Mangematin e Nesta (1999), } \\
\text { Zahra e George (2002) }\end{array}$ \\
\hline $\begin{array}{l}\text { AD4 - Desenvolvimento interno de competências } \\
\text { tecnológicas }\end{array}$ & Arbussà e Coenders (2007), Tu et al. (2006) \\
\hline
\end{tabular}




\begin{tabular}{|l|l|}
\hline AS1 - Assimilação da tecnologia & Jansen et al. (2005), Matusik e Heeley (2005), Wong et al. (1999) \\
\hline AS2 - Recursos Humanos & $\begin{array}{l}\text { Caloghirou et al. (2004), Hayton e Zahra (2005), Liao et al. (2007), } \\
\text { Nieto e Quevedo (2005), Tu et al. (2006), Vinding (2006) }\end{array}$ \\
\hline AS3 - Benchmarking Industrial & Tu et al. (2006) \\
\hline AS4 - Envolvimento na difusão do conhecimento & $\begin{array}{l}\text { Arbussà e Coenders (2007), Caloghirou et al. (2004), Fosfuri e Tribó } \\
\text { (2008), Soo et al. (2007) }\end{array}$ \\
\hline $\begin{array}{l}\text { AS5 - Participação em cursos de formação e } \\
\text { eventos profissionais }\end{array}$ & Caloghirou et al. (2004), Jansen et al. (2005), Soo et al. (2007) \\
\hline AS6 - Gestão do Conhecimento & Matusik e Heeley (2005), Szulanski (1996) \\
\hline Capacidade Absortiva Realizada \\
\hline Capacidade de Transformação (TR) \\
\hline $\begin{array}{l}\text { TR1 - Transmissão do conhecimento baseada em } \\
\text { TI }\end{array}$ & Jansen et al. (2005), Nieto e Quevedo (2005), Wong et al. (1999) \\
\hline TR2 - Capacidade de renovação & Jansen et al. (2005) \\
\hline TR3 - Capacidade de Adaptação & Jansen et al. (2005), Nieto e Quevedo (2005) \\
\hline $\begin{array}{l}\text { TR4 - Troca de informações científicas e } \\
\text { tecnológicas }\end{array}$ & $\begin{array}{l}\text { Jansen et al. (2005), Lenox e King (2004), Szulanski (1996), Soo et } \\
\text { al. (2007), Tu et al. (2006) }\end{array}$ \\
\hline TR5 - Integração de Pesquisa e desenvolvimento & Vinding (2006) \\
\hline Capacidade de Aplicação (AP) & Jansen et al. (2005) \\
\hline AP1 - Exploração de novos conhecimentos & Lenox e King (2004), Soo et al. (2007) \\
\hline AP2 - Aplicação da experiência & $\begin{array}{l}\text { George et al. (2001), Mangematin e Nesta (1999), Zahra e George } \\
\text { (2002) }\end{array}$ \\
\hline AP3 - Desenvolvimento de patentes & Jansen et al. (2005) \\
\hline AP4 - Proatividade Tecnológica
\end{tabular}

Fonte: traduzido e adaptado de Camisón e Forés (2010, p.711)

Para validar empiricamente o instrumento de mensuração, os autores realizaram uma pesquisa nas firmas espanholas. O tamanho da amostra foi de 2000 firmas, de 14 setores produtivos, distribuídos em quatro grupos de porte de acordo com a taxonomia utilizada pela União Europeia de micro, pequenas, médias e grandes empresas. A fim de promover a validação empírica das medidas, a pesquisa de Camisón e Forés (2010) aplicou técnicas de análise fatorial confirmatória e utilizou modelagem de equações estruturais.

A Tabela 2 apresenta os elementos de mensuração da capacidade potencial e realizada que o os autores aplicaram na pesquisa.

\section{Tabela 2: Elementos propostos para a mensuração da Capacidade Absortiva Potencial e} Realizada

AD1 - Capacidade para capturar informações e conhecimentos relevantes e atualizados sobre os concorrentes atuais e
potenciais.
AD2 - Grau de orientação para gestão "à espera de ver o que acontece", em vez da preocupação e orientação para
monitorar as tendências do ambiente de forma ampla e contínua e descobrir pro ativamente novas oportunidades a serem
exploradas.
AD3 - Frequência e importância da cooperação com organizações de P \& D, tais como universidades, escolas de negócios,
institutos tecnológicos, e outros, para gerar conhecimentos e inovações.
AD4 - Eficácia no estabelecimento de programas orientados para o desenvolvimento de competências internas para
aquisição tecnológica de centros de P \& D, fornecedores ou clientes.
AS1 - Capacidade de assimilar novas tecnologias e inovações que são úteis ou têm potencial comprovado.
AS2 - Capacidade de usar o nível de conhecimento, experiência e competência de funcionários na assimilação e
interpretação de novos conhecimentos.
AS3 - Vantagem da empresa quando se trata de assimilar o conhecimento básico e tecnologias a partir de experiências
bem-sucedidas de outras firmas do mesmo setor.
AS4 - Grau em que os funcionários da firma participam e apresentam trabalhos em conferências científicas e congressos,
são integrados com professores em universidades ou escolas de negócios ou recebem pessoal externo em projetos de
pesquisa.
AS5 - Comparecimento em cursos de formação, feiras e reuniões.
AS6 - Habilidade para desenvolver programas de gestão do conhecimento, garantindo a capacidade da firma para
compreender e analisar cuidadosamente o conhecimento e a tecnologia de outras organizações.


TR1 - Capacidade para usar informações tecnológicas a fim de melhorar o fluxo de informações, desenvolver a troca efetiva de conhecimentos e promover a comunicação interna, incluindo reuniões virtuais entre os profissionais que estão fisicamente separados, por exemplo.

TR2 - Consciência a respeito de suas competências na geração de inovação, especialmente no que diz respeito às tecnologias-chave e capacidade de eliminar o conhecimento interno obsoleto, estimulando a busca por inovações alternativas e sua adaptação.

TR3 - Capacidade de adaptar tecnologias criadas por outros para as necessidades específicas da firma.

TR4 - Grau em que a firma impede que todos os funcionários transmitam voluntariamente informações científicas e tecnológicas úteis adquiridas uns dos outros.

TR5 - Capacidade para coordenar e integrar todas as fases do processo de P\&D e as suas inter-relações com as tarefas funcionais de engenharia, produção e marketing.

AP1 - Capacidade de usar e explorar novos conhecimentos no local de trabalho para responder rapidamente às mudanças do ambiente.

AP2 - Grau de aplicação de conhecimento e experiência adquirida nas áreas tecnológicas e de negócios priorizadas na estratégia da firma que lhe permita manter-se na vanguarda tecnológica.

AP3 - Capacidade de colocar o conhecimento tecnológico registrado em patentes de produtos e processos.

AP4 - Capacidade de responder às exigências da demanda ou a pressão da concorrência, inovando para ganhar competitividade, ampliando o portfólio de novos produtos, recursos e ideias de tecnologia.

Fonte: tradução e adaptação de Camisón \& Forés (2010, p.714).

Para os autores, a vantagem deste instrumento de medição proposto é que ele não está limitado ao conhecimento tecnológico e, consequentemente, permite a análise de processos de aquisição e assimilação (CA Potencial) e de transformação e de exploração (CA Realizada) de outros tipos de conhecimento externo.

Apesar de algumas limitações citadas pelos autores, os resultados do estudo confirmam a validade das escalas propostas e apoiam a sua consolidação como instrumento para medir a capacidade de absorção.

\subsection{Influência dos recursos da firma nas diferentes dimensões da capacidade de absorção.}

O objetivo de Jiménez-Barrionuevo et al. (2011) foi o de contribuir com a literatura usando a visão baseada em recursos para apresentar um instrumento de mensuração da CA. O instrumento proposto, como ocorreu em Camisón e Forés (2010), diferenciou a CA entre as fases de aquisição, assimilação, transformação e exploração do conhecimento, bem como entre as duas dimensões da CA (potencial e realizada). Os autores realizaram uma extensa revisão bibliográfica e forneceram um resumo mas medidas mais frequentemente utilizadas na mensuração da CA. A Tabela 3 apresenta tais informações.

Tabela 3: Medidas mais frequentemente utilizadas na mensuração da Capacidade de Absorção

\begin{tabular}{|l|l|}
\hline Medidas utilizadas & Autores \\
\hline $\begin{array}{l}\text { Existência de um ou mais laboratórios de Pesquisa e Desenvolvimento (P\&D) da firma e } \\
\text { a regularidade das atividades internas de P\&D. }\end{array}$ & Becker e Peters (2000) \\
\hline Gestão do conhecimento da tecnologia da informação (TI) nos processos da firma. & Boynton et al. (1994) \\
\hline $\begin{array}{l}\text { Escala de 5 itens para medir a capacidade da empresa de assimilar e reproduzir os novos } \\
\text { conhecimentos obtidos a partir de fontes externas. }\end{array}$ & Chen (2004) \\
\hline $\begin{array}{l}\text { Número total de publicações com base nos valores gastos (em dólares) em pesquisa } \\
\text { anualmente. }\end{array}$ & Cockburn e Henderson (1998) \\
\hline
\end{tabular}




\begin{tabular}{|c|c|}
\hline Esforço de P\&D (gastos com P\&D/vendas anuais). & $\begin{array}{l}\text { Cohen e Levinthal (1990), } \\
\text { Stock et al. (2001), Tsai } \\
(2001) ; \text { Zahra e Hayton } \\
(2008)\end{array}$ \\
\hline $\begin{array}{l}\text { Despesas em P\&D (para medir a capacidade de adquirir conhecimento) e número de } \\
\text { patentes (para medir a capacidade de aplicar o conhecimento). }\end{array}$ & George et al. (2001) \\
\hline $\begin{array}{l}\text { Escala de } 24 \text { itens para medir a aquisição de novos conhecimentos externos à firma e a } \\
\text { disseminação deste conhecimento na firma. }\end{array}$ & Heeley (1997) \\
\hline $\begin{array}{l}\text { Escala de } 21 \text { itens utilizados para medir a capacidade de absorção potencial (aquisição e } \\
\text { assimilação do conhecimento) e capacidade de absorção realizada (transformação e } \\
\text { exploração do conhecimento) (escala incluída no estudo de Jiménez-Barrionuevo et al., } \\
\text { 2011) }\end{array}$ & Jansen et al. (2005) \\
\hline $\begin{array}{l}\text { Adaptação das escalas de outros estudos relacionados e criação de uma nova escala de } 24 \\
\text { itens para medir a compreensão, assimilação e aplicação do conhecimento (incluída no } \\
\text { estudo de Jiménez-Barrionuevo et al., 2011) }\end{array}$ & Lane et al. (2001) \\
\hline $\begin{array}{l}\text { Escala formada por } 15 \text { itens utilizados para medir a capacidade de adaptação, produção e } \\
\text { aplicação do conhecimento. }\end{array}$ & Lin et al. (2002) \\
\hline Total de pessoal técnico e profissional em relação ao número total de funcionários & Luo (1997) \\
\hline $\begin{array}{l}\text { Despesas de } \mathrm{P} \& \mathrm{D} \text {, número de pesquisadores, duração das atividades de } \mathrm{P} \& \mathrm{D} \text {, número de } \\
\text { laboratórios de } \mathrm{P} \& \mathrm{D} \text {, ligações com institutos públicos de pesquisa, número de } \\
\text { publicações e número de patentes. }\end{array}$ & Mangematin e Nesta (1999) \\
\hline $\begin{array}{l}\text { Nível de sobreposição tecnológica entre os futuros parceiros de uma aliança empresaria } \\
\text { antes do acordo ocorrer (medido pelo número de patentes da firma j citados nas patentes } \\
\text { da firma I / número total de citações presentes nas patentes da firma i antes do acordo } \\
\text { ocorrer entre j e i). }\end{array}$ & Mowery et al. (1996) \\
\hline $\begin{array}{l}\text { Escala formada por } 32 \text { itens para medir a comunicação com o meio ambiente, o nível de } \\
\text { conhecimento e experiência, a diversidade e a coincidência das estruturas do } \\
\text { conhecimento e da posição estratégica da organização. }\end{array}$ & Nieto e Quevedo (2005) \\
\hline Esforço de P\&D (despesa em P\&D / vendas anuais) e o esforço no treinamento. & Petroni e Panciroli (2002) \\
\hline $\begin{array}{l}\text { Conjunto de variáveis binárias utilizadas para medir a propensão das firmas para } \\
\text { transferir conhecimento. }\end{array}$ & Shenkar e Li (1999) \\
\hline $\begin{array}{l}\text { Atividades de P\&D destinadas a desenvolver novos conhecimentos e outras atividades, } \\
\text { tais como inteligência do conhecimento e atividades de disseminação do conhecimento. }\end{array}$ & Spithoven et al. (2010) \\
\hline $\begin{array}{l}\text { Escala formada por } 9 \text { itens para medir a capacidade de absorção global (escala incluídos } \\
\text { no estudo de Jiménez-Barrionuevo et al., 2011) }\end{array}$ & Szulanski (1996) \\
\hline $\begin{array}{l}\text { Desenvolvimento de uma escala que mede a capacidade de absorção como um } \\
\text { constructo multidimensional que incorpora questões da firma, bem como o capital } \\
\text { humano. }\end{array}$ & Thuc Anh, et al. (2006) \\
\hline Existência de departamentos de P\&D da própria firma com pessoal em tempo integral. & Veugelers (1997) \\
\hline
\end{tabular}

Fonte: traduzido e adaptado de Jiménez-Barrionuevo et al. (2011, p. 99).

Dada a necessidade de garantir a validação empírica rigorosa do instrumento de medição, o estudo avaliou três questões fundamentais: a validade do conteúdo, do conceito e a confiabilidade da escala. O estudo procurou medir a Capacidade de Absorção através da diferenciação entre as dimensões de aquisição, assimilação, transformação e exploração do conhecimento. Sendo mais tarde combinadas as duas primeiras e as duas últimas para confirmar se esta combinação é capaz de representar a Capacidade de Absorção Potencial e Realizada das firmas.

A população do estudo, que totalizou 5.163 firmas, consistiu em empresas espanholas dos setores automotivo e químico. O porte das firmas não foi considerada uma variável discriminante. A amostra foi selecionada aleatoriamente, resultando num total de 964 firmas. A taxa de resposta obtida foi de $17 \%$, semelhante a outras pesquisas sobre a Capacidade de Absorção (Garcia Morales et al., 2007; Lin et al., 2002; Nieto e Quevedo, 2005; Zahra e Hayton, 2008 apud Jiménez-Barrionuevo et al., 2011). 
Conforme os autores, a escala de medida desenvolvida tem validade de conteúdo, tendo em vista que foram observadas as principais ferramentas de medição desenvolvidas em estudos anteriores e porque a escolha das fases e dimensões determinantes da capacidade de absorção foram baseadas no trabalho de Zahra e George (2002). A escala resultante contendo 18 itens é apresentada na Tabela 4.

\section{Tabela 4: Elementos finais de mensuração da capacidade absortiva}

\begin{tabular}{|c|c|}
\hline \multicolumn{2}{|l|}{ Aquisição (Potencial) } \\
\hline 1. Interação & Existe uma grande interação pessoal entre as duas organizações. \\
\hline 2. Confiança & $\begin{array}{l}\text { A relação entre as duas organizações é caracterizada pela confiança } \\
\text { mútua. }\end{array}$ \\
\hline 3. Respeito & A relação entre as duas organizações é caracterizada pelo respeito mútuo. \\
\hline 4. Amizade & A relação entre as organizações tem caráter de amizade pessoal. \\
\hline 5. Reciprocidade & $\begin{array}{l}\text { A relação entre as duas organizações é caracterizada por um elevado } \\
\text { nível de reciprocidade. }\end{array}$ \\
\hline \multicolumn{2}{|c|}{ Assimilação (Potencial) } \\
\hline 1. Linguagem Comum & $\begin{array}{l}\text { Os membros das duas organizações partilham a sua própria linguagem } \\
\text { comum. }\end{array}$ \\
\hline 2. Complementariedade & $\begin{array}{l}\text { Existe uma alta complementaridade entre os recursos e capacidades das } \\
\text { duas organizações. }\end{array}$ \\
\hline 3. Similaridade & $\begin{array}{l}\text { As capacidades principais de ambas as organizações são muito } \\
\text { semelhantes / sobrepostas. }\end{array}$ \\
\hline 4. Compatibilidade 1 & As culturas organizacionais das duas organizações são compatíveis. \\
\hline 5. Compatibilidade 2 & $\begin{array}{l}\text { Os estilos de funcionamento e de gestão das duas organizações são } \\
\text { compatíveis. }\end{array}$ \\
\hline \multicolumn{2}{|c|}{ Transformação (Realizada) } \\
\hline 1. Comunicação & $\begin{array}{l}\text { Há muitas conversas informais na organização que envolvem a atividade } \\
\text { comercial. }\end{array}$ \\
\hline 2. Reuniões & $\begin{array}{lllll}\begin{array}{l}\text { Reuniões interdepartamentais são organizadas } \\
\text { desenvolvimento e tendências da organização. }\end{array} & & \text { discutir } & \text { o } \\
\end{array}$ \\
\hline 3. Documentos & $\begin{array}{lccc}\text { As diferentes unidades publicam } & \text { documentos } & \text { informativos } \\
\text { periodicamente (relatórios, boletins, etc.) } & & \end{array}$ \\
\hline 4. Transmissão & Os dados importantes são transmitidos regularmente a todas as unidades. \\
\hline 5. Tempo & $\begin{array}{l}\text { Quando algo importante ocorre, todas as unidades são informadas, num } \\
\text { curto espaço de tempo. }\end{array}$ \\
\hline 6. Fluxos & $\begin{array}{l}\text { A organização tem a capacidade ou habilidades necessárias para } \\
\text { assegurar que os fluxos de conhecimento dentro da organização sejam } \\
\text { compartilhados entre as diferentes unidades. }\end{array}$ \\
\hline \multicolumn{2}{|l|}{ Exploração (Realizada) } \\
\hline 1. Responsabilidade & $\begin{array}{l}\text { Há uma clara divisão de funções e responsabilidades a respeito do uso de } \\
\text { informações e conhecimentos obtidos externamente. }\end{array}$ \\
\hline 2. Aplicação & $\begin{array}{l}\text { Há capacidades e habilidades necessárias para aproveitar as informações } \\
\text { e conhecimentos obtidos externamente. }\end{array}$ \\
\hline
\end{tabular}

Fonte: traduzido e adaptado de Jiménez-Barrionuevo et al. (2011, p.201).

Os resultados da pesquisa realizada por Jiménez-Barrionuevo et al. (2011) mostram que os elementos de interação, confiança, respeito, amizade, reciprocidade, linguagem comum, complementaridade, semelhança, compatibilidade 1 e compatibilidade 2 formam um único fator, denominado de "capacidade de absorção potencial", o qual é composto pelas fases de aquisição e assimilação de conhecimento. Da mesma forma, os elementos de comunicação, reuniões, documentos, transmissão, tempo, fluxos, responsabilidade e aplicação 
formam um segundo fator, identificado como sendo a "capacidade de absorção realizada", a qual é composta das fases de transformação e exploração do conhecimento.

Os autores afirmam ter definido um grupo de elementos capazes de mensurar as habilidades para adquirir, assimilar, transformar e explorar o conhecimento, bem como as dimensões da capacidade absortiva potencial. O novo instrumento foi construído e validado seguindo as recomendações mais freqüentes na literatura científica sobre o desenvolvimento de escalas em ciências sociais, tornando a escala proposta válida e confiável para medir a Capacidade de Absorção de firmas, e, assim, podendo ser explorada em pesquisas empíricas futuras.

\subsection{Capacidade de Absorção como recurso dinâmico e suas múltiplas dimensões}

Flatten et al. (2011) procuraram desenvolver e validar uma medida multidimensional da capacidade absortiva, com base em uma revisão de literatura e em duas pesquisas aplicadas em empresas alemãs. Os autores fornecem uma visão geral das várias proxies usadas em estudos anteriores, conforme apresentado na Tabela 5.

Tabela 5: Estudos utilizando proxies para mensurar a Capacidade Absortiva

\begin{tabular}{|c|c|c|}
\hline Tópicos de Pesquisa & Proxy & Autores \\
\hline $\begin{array}{l}\text { Aquisição tecnológica e desempenho da } \\
\text { firma }\end{array}$ & Número de patentes & Ahuja e Katila (2001) \\
\hline Heterogeneidade em cooperações de P\&D & Intensidade de $\mathrm{P} \& \mathrm{D}$ & $\begin{array}{l}\text { Belderbos, Carree, Diederen, } \\
\text { Lokshin, e Veugelers (2004) }\end{array}$ \\
\hline $\begin{array}{l}\text { Influência dos processos de gestão de TI } \\
\text { com relação ao uso de TI em grandes } \\
\text { empresas }\end{array}$ & Gestão do Conhecimento de TI & $\begin{array}{l}\text { Boynton, Zmud, and Jacobs } \\
\text { (1994) }\end{array}$ \\
\hline Produtividade de $\mathrm{P} \& \mathrm{D}$ & $\begin{array}{lll}\begin{array}{l}\text { Número } \\
\text { acadêmicas }\end{array} & \text { de } & \text { publicações } \\
\end{array}$ & Cockburn e Henderson (1998) \\
\hline Investimentos em P\&D & Intensidade de P\&D & Cohen e Levinthal (1989) \\
\hline $\begin{array}{l}\text { Desenvolvimento da CA Potencial em nível } \\
\text { de gestão }\end{array}$ & $\begin{array}{l}\text { Gestão do conhecimento (fluxos } \\
\text { de informações) }\end{array}$ & Lenox e King (2004) \\
\hline Investimentos na indústria chinesa. & $\begin{array}{l}\text { Investimentos em trabalhadores de } \\
\text { P\&D }\end{array}$ & Liu e White (1997) \\
\hline Aprendizagem & Intensidade de P\&D & $\begin{array}{l}\text { Meeus, Oerlemans e Hage } \\
(2001)\end{array}$ \\
\hline $\begin{array}{l}\text { Alianças estratégicas e transferência de } \\
\text { conhecimento na firma }\end{array}$ & Patentes e intensidade de P\&D & Mowery et al. (1996) \\
\hline $\begin{array}{l}\text { Transferência de tecnologia e capacidade } \\
\text { nacional de inovação }\end{array}$ & $\begin{array}{l}\text { Os investimentos em educação } \\
\text { superior, técnica e acadêmica }\end{array}$ & Mowery e Oxley (1995) \\
\hline Sucesso da planta de produtos & $\begin{array}{llll}\begin{array}{l}\text { Produtividade } \\
\text { trabalho }\end{array} & \text { e qualidade } & \text { do } \\
\end{array}$ & $\begin{array}{l}\text { Mukherjee, Mitchell, e Talbot } \\
(2000)\end{array}$ \\
\hline $\begin{array}{l}\text { Efeitos das operações em pequena e média } \\
\text { empresas }\end{array}$ & $\begin{array}{l}\text { Grau de funcionários que são } \\
\text { incumbidos de P\&D }\end{array}$ & Muscio (2007) \\
\hline 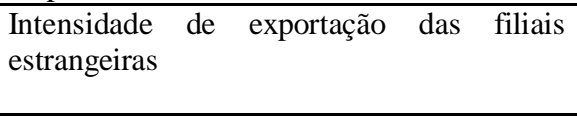 & $\begin{array}{l}\text { Nível salarial das empresas } \\
\text { estrangeiras em relação ao nível } \\
\text { das empresas nacionais }\end{array}$ & Nielsen e Pawlik (2007) \\
\hline Inovações geradas pela firma & Intensidade de P\&D & Oltra e Flor (2003) \\
\hline Desenvolvimento de novos produtos & Intensidade de P\&D & Stock, Greis, e Fischer (2001) \\
\hline $\begin{array}{l}\begin{array}{l}\text { Desempenho da firma e sucesso nas } \\
\text { inovações }\end{array} \\
\end{array}$ & Intensidade de P\&D & Tsai $(2001)$ \\
\hline Forma de organização e habilidade & Sistemas de incentivos & Vandenbosch, Volberda, e De \\
\hline
\end{tabular}




\begin{tabular}{|l|l|l|}
\hline & & Boer (1999) \\
\hline Nível de atividades inovativas & $\begin{array}{l}\text { Funcionários alocados no P\&D, } \\
\text { pós-graduados realizando } \\
\text { atividade de P\&D, proporção de } \\
\text { P\&D em pesquisa básica }\end{array}$ & \\
\hline Sucesso nas inovações & Gestão de Recursos Humanos & Vinding (2006) \\
\hline
\end{tabular}

Fonte: traduzido e adaptado de Flatten et al. (2011, p.99).

Flatten et al. (2011) concordam que o uso dessas proxies podem ter contribuído para descobertas conflitantes sobre a natureza e as contribuições da Capacidade Absortiva. Essas falhas sugerem a necessidade de uma medida mais válida que capture as múltiplas dimensões do conceito. Os autores mencionam que os gastos em P\&D e as patentes geradas não são a única fonte de Capacidade Absortiva uma vez que as habilidades dos funcionários, experimentos organizacionais e experiências prévias contribuem de forma significativa para Capacidade Absortiva das empresas. Assim, Lane et al. (2006, p. 858) apud Flatten et al. (2011, p. 99), sugerem que a "Capacidade de Absorção deveria ser empiricamente explorada em contextos não relacionados a $\mathrm{P} \& \mathrm{D}$, usando métricas que capturam cada dimensão do processo da capacidade absortiva de uma maneira apropriada para aquele determinado contexto". Conforme Lane, estudos que utilizam proxies para medir a Capacidade Absortiva não podem capturar a complexidade das suas várias dimensões visto que tais medidas geralmente tratam a "Capacidade de Absorção como um recurso estático e não como um processo ou uma capacidade" (Lane et al., 2006, p. 838 apud Flatten et al., 2011, p. 99).

Flatten et al. (2011), realizaram um estudo empírico procurando desenvolver uma medida que pudesse ser valiosa para os proxies que são geralmente utilizados na literatura. Com isso, poderiam ajudar a resolver a questão de saber se Capacidade Absortiva possui três dimensões, como proposto por Cohen e Levinthal (1990), ou quatro, como sugerido por Zahra e George (2002).

Para operacionalizar o conceito de Capacidade de Absorção foi aplicada uma pesquisa quantitativa em duas etapas, sendo que a população-alvo na primeira etapa foi de 2.497 executivos e na segunda de 3.844 executivos, tendo sido obtida uma taxa de resposta de $10 \%$. $\mathrm{Na}$ primeira etapa, foram testados os itens que não capturam adequadamente os componentes teóricos da construção da Capacidade Absortiva. Após a aplicação de pré-testes, o questionário foi aplicado em empresas de diferentes portes e tempo de existência, com foco em setores de pesquisa intensiva da economia alemã - onde entende-se ser a Capacidade Absortiva especialmente importante - como as indústrias química, mecânica e de engenharia elétrica (Burgel \& Murray, 2000 apud Flatten et al., 2011). A Tabela 6 descreve os elementos da escala validados pelos autores. 
Tabela 6: Elementos de mensuração da Capacidade Absortiva.

\begin{tabular}{|l|l|}
\hline $\begin{array}{l}\text { Aquisição: especifique em que medida sua empresa utiliza recursos externos (por exemplo, redes pessoais, consultores, } \\
\text { seminários, internet, banco de dados, revistas profissionais, publicações acadêmicas, pesquisas de mercado, regulamentos } \\
\text { e leis) para obter informações: }\end{array}$ \\
\hline Aquisição A & $\begin{array}{l}\text { A busca de informações relevantes sobre os negócios da indústria está cada vez mais útil } \\
\text { para a nossa firma. }\end{array}$ \\
\hline Aquisição B & Nossos gestores motivam os funcionários a usar fontes de informação. \\
\hline Aquisção C & $\begin{array}{l}\text { Nossos gestores esperam que os funcionários lidem com informações além da nossa } \\
\text { indústria. }\end{array}$ \\
\hline Assimilação: avalie até que ponto as seguintes afirmações referem-se à estrutura de comunicação da sua empresa:
\end{tabular}
Fonte: traduzido e adaptado de Flatten et al. (2011, p.110).

A medida proposta por Flatten et al. (2011) avaliou o grau em que uma empresa se envolve em atividades de aquisição, assimilação, transformação e exploração comercial do conhecimento. O objetivo dos autores foi propor uma estrutura de mensuração que contribua na realização de análises mais sistemáticas a respeito da CA. A estrutura apresentada pode também servir como uma padrão de mensuração que permita a comparação de resultados entre diferentes estudos.

A partir da análise das diferentes contribuições apresentadas por Camisón \& Forés (2010); Jiménez-Barrionuevo et al. (2011) e Flatten et al. (2011), verifica-se que as propostas apresentadas são genéricas, no sentido de corresponderem a estruturas de mensuração da CA para qualquer firma, independente do perfil deste agente. Entretanto, é preciso avançar mais no intuito de responder ao objetivo deste artigo, ou seja, apresentar uma estrutura de mensuração adaptada para avaliar a CA de firmas que interagem com Universidades. Faz-se isso na próxima seção. 


\section{MENSURAÇÃO DA CAPACIDADE DE ABSORÇÃo DE FIRMAS QUE INTERAGEM COM UNIVERSIDADES}

Objetiva-se aqui apresentar uma estrutura validada de mensuração da CA de firmas que interagem com Universidades. Assim, releva resgatar outros dois tipos de CA mencionados ao longo deste texto e que são: a CA industrial e a CA científica. Conforme Vega-Jurado et al. (2008), os fatores que determinam o desenvolvimento de cada um destes dois tipos de CA são diferentes, pois a primeira diz respeito à capacidade da firma de lidar com conhecimento externo proveniente, essencialmente, de outras firmas, de clientes e de fornecedores, e a segunda diz respeito ao potencial que firma tem de utilizar o conhecimento desenvolvido na as universidades e institutos de pesquisa, centralmente. O destaque que a literatura faz aqui é apontar para o fato de que o tipo de conhecimento acessado, adquirido e assimilado inicialmente pela firma também determina e exige diferentes capacidades deste agente para melhor transformá-lo e explorá-lo comercialmente.

Inicialmente, foram reunidos os elementos validados nos estudos de Camisón e Forés (2010), Jiménez-Barrionuevo et al. (2011) e Flatten et al. (2011) nas dimensões de aquisição, assimilação, transformação e exploração. Além disso, foi considerada na proposta apresentada a seguir a divisão das quatro dimensões em duas categorias: CA Potencial e CA Realizada, conforme sugerem Zahra e George (2002) e demais autores aqui enfatizados. Entende-se que considerar essas categorias é fundamental para avaliar a CA das firmas que interagem com universidades, pois pode permitir avaliar se há uma das dimensões - potencial ou realizada que se mostra mais presente nas firmas que rotineiramente utilizam conhecimento proveniente das universidades para a geração de inovações; ou ainda, compreender se há relação entre a dimensão mais presente na firma, os tipos de interação realizados, os tipos de universidades parcerias (públicas, privadas, geograficamente próximas ou distantes, etc.) e o tempo do relacionamento.

Defende-se aqui, conforme já afirmado, que empresas com maior nível de CA Potencial usufruem melhor dos benefícios gerados pela interação com universidades, uma vez que possibilita à organização ser receptiva ao conhecimento externo, isto é, adquirir, analisar, interpretar e compreender esse ativo. De acordo com Zahra e George (2002), a CA potencial está relacionada à geração de inovações que produzem vantagem competitiva. Portanto, o instrumento de mensuração proposto deve ser útil para avaliar se as firmas que possuem interação com universidade, objetivando a geração de inovações, detêm um nível de CA Potencial que lhes permita adquirir e assimilar os conhecimentos gerados por essa interação. 
Sendo assim, a estrutura proposta é o resumo de uma seleção dos elementos de avaliação de CA apresentados nos três estudos relatados anteriormente e classificados nas duas categorias de CA Potencial e CA Realizada e nas quatro dimensões de aquisição, assimilação, transformação e exploração. Em relação a seleção dos elementos de mensuração, procurou-se selecionar aqueles validados nos três estudos revisados e que pareciam melhor ajustar-se à realidade de firmas que utilizam universidades como fonte de conhecimento externo. A Tabela 7 apresenta a estrutura proposta.

Tabela 7: Proposta de estrutura de mensuração da capacidade absortiva de firmas que interagem com universidades

\begin{tabular}{|c|c|}
\hline Elementos de Capacidade Absortiva Potencial & Autores \\
\hline \multicolumn{2}{|l|}{ Aquisicão } \\
\hline $\begin{array}{l}\text { 1. A busca de informações relevantes sobre os negócios de nosso setor } \\
\text { industrial é cada vez mais frequente em nossa empresa. }\end{array}$ & Flatten et al. (2011) \\
\hline $\begin{array}{l}\text { 2. Existe grande interação pessoal entre a empresa e a organização externa } \\
\text { utilizada para facilitar os processos inovativos. }\end{array}$ & Jiménez-Barrionuevo et al. (2011) \\
\hline $\begin{array}{l}\text { 3. A relação entre as duas organizações é caracterizada pela confiança } \\
\text { mútua. }\end{array}$ & Jiménez-Barrionuevo et al. (2011) \\
\hline $\begin{array}{l}\text { 4. Nossa empresa é eficaz na criação de programas orientados ao } \\
\text { desenvolvimento de competências internas para aquisição tecnológica de } \\
\text { centros de Pesquisa e Desenvolvimento (P\&D), fornecedores ou clientes. }\end{array}$ & Camisón e Forés (2010) \\
\hline $\begin{array}{l}\text { 5. A cooperação com centros de P\&D (Universidades, Institutos } \\
\text { tecnológicos, etc.) é frequente e importante em nossa empresa para criar } \\
\text { novos conhecimentos e inovações. }\end{array}$ & Camisón e Forés (2010) \\
\hline \multicolumn{2}{|l|}{ Assimilação } \\
\hline $\begin{array}{l}\text { 1. Em nossa empresa, há um fluxo rápido de informação, por exemplo, se } \\
\text { uma unidade de negócios obtém informações importantes, se comunica } \\
\text { imediatamente com todas as outras unidades de negócios ou } \\
\text { departamentos. }\end{array}$ & Flatten et al. (2011) \\
\hline $\begin{array}{l}\text { 2. Nossos gestores enfatizam o apoio entre departamentos para resolver } \\
\text { problemas. }\end{array}$ & Flatten et al. (2011) \\
\hline $\begin{array}{l}\text { 3. Nossa empresa possui capacidade de assimilar novas tecnologias e } \\
\text { inovações que são úteis ou têm potencial comprovado. }\end{array}$ & Camisón e Forés (2010) \\
\hline $\begin{array}{l}\text { 4. Nossa empresa possui habilidade para utilizar conhecimentos, } \\
\text { experiências e competências dos funcionários na assimilação e } \\
\text { interpretação de novos conhecimentos. }\end{array}$ & Camisón e Forés (2010) \\
\hline $\begin{array}{l}\text { 5. Nossos funcionários participam de cursos de formação e eventos } \\
\text { profissionais. }\end{array}$ & Camisón e Forés (2010) \\
\hline Elementos de Capacidade Absortiva Realizada & Autores \\
\hline \multicolumn{2}{|l|}{ Transformaçãa } \\
\hline $\begin{array}{l}\text { 1. As diferentes unidades da empresa publicam documentos informativos } \\
\text { periodicamente (relatórios, boletins, etc.) }\end{array}$ & Jiménez-Barrionuevo et al. (2011) \\
\hline $\begin{array}{l}\text { 2. A organização tem capacidade ou habilidade necessárias para assegurar } \\
\text { que os fluxos de conhecimento dentro da organização sejam } \\
\text { compartilhados entre as diferentes unidades. }\end{array}$ & Jiménez-Barrionuevo et al. (2011) \\
\hline $\begin{array}{l}\text { 3. Nossos funcionários possuem capacidade de estruturar e usar o } \\
\text { conhecimento adquirido. }\end{array}$ & Flatten et al. (2011) \\
\hline $\begin{array}{l}\text { 4. Nossa empresa possui capacidade de adaptar tecnologias projetadas por } \\
\text { outras organizações às nossas necessidades. }\end{array}$ & Camisón e Forés (2010) \\
\hline $\begin{array}{l}\text { 5. Nossa empresa possui capacidade de coordenar e integrar todas as fases } \\
\text { do processo de P\&D com as tarefas funcionais de engenharia, produção e } \\
\text { marketing. }\end{array}$ & Camisón e Forés (2010) \\
\hline \multicolumn{2}{|l|}{ Exploração } \\
\hline $\begin{array}{l}\text { 1. Há uma clara divisão de funções e responsabilidades a respeito do uso de } \\
\text { informações e conhecimentos obtidos externamente. }\end{array}$ & Jiménez-Barrionuevo et al. (2011) \\
\hline Nossos gestores apoiam o desenvolvimento de protótipos. & Flatten et al. (2011) \\
\hline Nossa empresa regularmente reconsidera as tecnologias e se adapta à elas & Flatten et al. (2011) \\
\hline
\end{tabular}




\begin{tabular}{|c|c|c|}
\hline & de acordo com os novos conhecimentos. & \\
\hline 4. & $\begin{array}{l}\text { Nossa empresa tem a capacidade de trabalhar de forma mais eficaz através } \\
\text { da adoção de novas tecnologias. }\end{array}$ & Flatten et al. (2011) \\
\hline & $\begin{array}{l}\text { Nossa empresa possui capacidade para aplicar o conhecimento } \\
\text { tecnológico em patentes de produtos e processos. }\end{array}$ & Camisón e Forés (2010) \\
\hline
\end{tabular}

Fonte: Elaboração própria.

A partir da elaboração da proposta de mensuração de CA apresentada acima, foi feito um esforço de pesquisa de campo para validá-la. Para tanto, o grupo de elementos descritos na Tabela 7 foi inserido em um questionário mais amplo construído para identificar características da interação universidade-empresa, capacidade de absorção e desempenho inovativo em produtos e processos da firma que interage. Foi realizada uma pesquisa survey com as empresas mencionadas pelos grupos de pesquisa no Censo de 2010 do Diretório de Grupos de Pesquisa (DGP) do CNPq, por realizarem interações com tais grupos. Optou-se por focar nas empresas que interagiam com grupos de pesquisa das áreas de Engenharia Mecânica, de Materiais e Metalúrgica das Universidades do Rio Grande do Sul, visto que a área das Engenharias é, no RS, a que mais possui grupos que afirmam ter interação com empresas. A população da pesquisa resultou em 71 empresas privadas localizadas no RS e de pequeno, médio e grande porte, conforme classificação do SEBRAE. Os respondentes foram identificados previamente por meio de contato telefônico e eram profissionais envolvidos com atividades de inovação das firmas e que participavam (ou tinham participado) do processo de interação com a(s) universidade(s).

$\mathrm{O}$ instrumento - previsto para ser aplicado via internet - foi submetido à avaliação em pré-testes realizados por meio de aplicação presencial com 7 empresas e aplicação on line com outras 6 empresas da população selecionada. A cada realização dos pré-testes os elementos de mensuração da capacidade absortiva eram avaliados no sentido de melhor extrair as percepções dos respondentes. Houve a necessidade de inclusão de mais dois indicadores para a avaliação da CA em cada uma das quatro dimensões - aquisição, assimilação, transformação e exploração -, além dos propostos originalmente. Também, na dimensão de aquisição foram utilizados dois indicadores validados nos estudos de VegaJurado et al., (2008) e de Murovec e Prodan (2009). O primeiro está relacionado à qualificação dos funcionários para trabalharem em projetos inovadores e, o segundo à valorização pelas empresas das atitudes dos funcionários que promovem mudanças internas.

A escala utilizada para capturar as respostas referentes à capacidade absortiva foi do tipo Likert, de concordância e de 5 pontos, já utilizada em estudos anteriores sobre a mensuração da CA. Após a validação do instrumento, foi realizada a etapa de aplicação do 
questionário em toda a população. O total de firmas respostas foi de 32, o que representa uma amostra de $45 \%$ da população.

O tratamento dos dados foi realizado em duas etapas: 1) uma análise exploratória dos dados para o exame das variáveis a serem utilizadas; e 2) uma análise de confiabilidade das variáveis relacionadas às dimensões da capacidade absortiva, a qual foi obtida através do cálculo do coeficiente de alfa de Cronbach. Cada dimensão da CA foi mensurada através de sete variáveis, conforme explicado acima; os coeficientes gerados foram: a) para a dimensão de aquisição $=0,724 ;$ b) para a assimilação $=0,821$; ) para a transformação $=0,845$; e d) para a dimensão de exploração $=0,855$. Os resultados indicam que os valores encontrados na análise de confiabilidade estão acima de 0,6 e, assim, é possível afirmar que as dimensões da estrutura proposta de mensuração da CA possuem consistência interna.

A Tabela 7 apresenta a estrutura final do instrumento de mensuração da CA.

Tabela 7: Estrutura validada para mensuração da capacidade absortiva de firmas que interagem com universidades

\begin{tabular}{|c|c|}
\hline Elementos de Capacidade Absortiva Potencial & Autores \\
\hline \multicolumn{2}{|l|}{ Aquisição } \\
\hline $\begin{array}{l}\text { 1. A busca de informações relevantes sobre os negócios de nosso setor } \\
\text { industrial é cada vez mais frequente em nossa empresa. }\end{array}$ & Flatten et al. (2011) \\
\hline $\begin{array}{l}\text { 2. Nossos funcionários possuem as qualificações necessárias para trabalhar } \\
\text { em projetos inovadores. }\end{array}$ & Vega-Jurado et al. (2008) \\
\hline $\begin{array}{l}\text { 3. As atitudes que promovem mudanças internas são valorizadas pela } \\
\text { empresa. }\end{array}$ & Murovec; Prodan (2009) \\
\hline $\begin{array}{l}\text { 4. Existe grande interação pessoal entre a empresa e a organização externa } \\
\text { utilizada para facilitar os processos inovativos. }\end{array}$ & Jiménez-Barrionuevo et al. (2011) \\
\hline $\begin{array}{l}\text { 5. A relação entre as duas organizações é caracterizada pela confiança } \\
\text { mútua. }\end{array}$ & Jiménez-Barrionuevo et al. (2011) \\
\hline $\begin{array}{l}\text { 6. Nossa empresa é eficaz na criação de programas orientados ao } \\
\text { desenvolvimento de competências internas para aquisição tecnológica de } \\
\text { centros de Pesquisa e Desenvolvimento }(\mathrm{P} \& \mathrm{D}) \text {, fornecedores ou clientes. }\end{array}$ & Camisón e Forés (2010) \\
\hline $\begin{array}{l}\text { 7. A cooperação com centros de P\&D (Universidades, Institutos } \\
\text { tecnológicos, etc.) é frequente e importante em nossa empresa para criar } \\
\text { novos conhecimentos e inovações. }\end{array}$ & Camisón e Forés (2010) \\
\hline \multicolumn{2}{|l|}{ Assimilação } \\
\hline $\begin{array}{l}\text { 1. Nossos gestores enfatizam o apoio entre departamentos para resolver } \\
\text { problemas. }\end{array}$ & Flatten et al. (2011) \\
\hline $\begin{array}{l}\text { 2. Em nossa empresa, há um fluxo rápido de informação, por exemplo, se } \\
\text { uma unidade de negócios obtém informações importantes, se comunica } \\
\text { imediatamente com todas as outras unidades de negócios ou departamentos. }\end{array}$ & Flatten et al. (2011) \\
\hline $\begin{array}{l}\text { 3. Nossos gestores exigem reuniões interdepartamentais periódicas para a } \\
\text { troca de informações sobre novos desenvolvimentos, problemas e } \\
\text { conquistas. }\end{array}$ & Flatten et al. (2011) \\
\hline $\begin{array}{l}\text { 4. Existe uma alta complementaridade entre os recursos e capacidades da } \\
\text { empresa e da organização externa utilizada como fonte de informação e } \\
\text { conhecimento. }\end{array}$ & Jiménez-Barrionuevo et al (2011) \\
\hline $\begin{array}{l}\text { 5. Nossa empresa possui capacidade de assimilar novas tecnologias e } \\
\text { inovações que são úteis ou têm potencial comprovado. }\end{array}$ & Camisón e Forés (2010) \\
\hline $\begin{array}{l}\text { 6. Nossa empresa possui habilidade para utilizar o nível de conhecimentos, } \\
\text { experiências e competências dos funcionários na assimilação e interpretação } \\
\text { de novos conhecimentos. }\end{array}$ & Camisón e Forés (2010) \\
\hline $\begin{array}{l}\text { 7. Nossos funcionários participam de cursos de formação e eventos } \\
\text { profissionais. }\end{array}$ & Camisón e Forés (2010) \\
\hline
\end{tabular}




\begin{tabular}{|c|c|}
\hline Elementos de Capacidade Absortiva Realizada & Autores \\
\hline \multicolumn{2}{|l|}{ Tranformação } \\
\hline $\begin{array}{l}\text { 1. As diferentes unidades da empresa publicam documentos informativos } \\
\text { periodicamente (relatórios, boletins, etc.) }\end{array}$ & Jiménez-Barrionuevo, et al. (2011) \\
\hline $\begin{array}{l}\text { 2. A organização tem a capacidade ou habilidade necessárias para } \\
\text { assegurar que os fluxos de conhecimento dentro da organização sejam } \\
\text { compartilhados entre as diferentes unidades. }\end{array}$ & Jiménez-Barrionuevo ,et al. (2011) \\
\hline $\begin{array}{l}\text { 3. Nossos funcionários possuem capacidade de estruturar e usar o } \\
\text { conhecimento adquirido. }\end{array}$ & Flatten, et al. (2011) \\
\hline $\begin{array}{l}\text { 4. Nossos funcionários conectam o conhecimento existente com novas } \\
\text { ideias com sucesso. }\end{array}$ & Flatten, et al. (2011) \\
\hline $\begin{array}{l}\text { 5. Nossos funcionários são capazes de aplicar os novos conhecimentos em } \\
\text { suas práticas de trabalho. }\end{array}$ & Flatten, et al. (2011) \\
\hline $\begin{array}{l}\text { 6. Nossa empresa possui capacidade de adaptar tecnologias projetadas por } \\
\text { outras organizações às nossas necessidades. }\end{array}$ & Camisón e Forés (2010) \\
\hline $\begin{array}{l}\text { 7. Nossa empresa possui capacidade de coordenar e integrar todas as fases } \\
\text { do processo de P\&D com as tarefas funcionais de engenharia, produção e } \\
\text { marketing. }\end{array}$ & Camisón e Forés (2010) \\
\hline \multicolumn{2}{|l|}{ Exploração } \\
\hline $\begin{array}{l}\text { 1. Há uma clara divisão de funções e responsabilidades a respeito do uso } \\
\text { de informações e conhecimentos obtidos externamente. }\end{array}$ & Jiménez-Barrionuevo, et al. (2011) \\
\hline 2. Nossos gestores apoiam o desenvolvimento de protótipos. & Flatten et al. (2011) \\
\hline $\begin{array}{l}\text { 3. Nossa empresa regularmente reconsidera as tecnologias e se adapta à } \\
\text { elas de acordo com os novos conhecimentos. }\end{array}$ & Flatten et al. (2011) \\
\hline $\begin{array}{l}\text { 4. Nossa empresa tem a capacidade de trabalhar de forma mais eficaz } \\
\text { através da adoção de novas tecnologias. }\end{array}$ & Flatten et al. (2011) \\
\hline $\begin{array}{l}\text { 5. Nossa empresa responde rapidamente às mudanças do ambiente de } \\
\text { negócios utilizando novos conhecimentos. }\end{array}$ & Camisón e Forés (2010) \\
\hline $\begin{array}{l}\text { 6. Nossa empresa possui capacidade para aplicar o conhecimento } \\
\text { tecnológico em patentes de produtos e processos. }\end{array}$ & Camisón e Forés (2010) \\
\hline $\begin{array}{l}\text { 7. Nossa empresa é capaz de responder às exigências da demanda e as } \\
\text { pressões da concorrência, buscando inovar cada vez mais para garantir sua } \\
\text { competitividade. }\end{array}$ & Camisón e Forés (2010) \\
\hline
\end{tabular}

Fonte: Elaborado pelas autoras

Em termos de CA Científica e Industrial, após a experiência desta pesquisa, entende-se que este tipo de capacidade não é explicitamente captada. Isso porque a diferença entre esses dois tipos de CA está na origem do conhecimento acessado e inicialmente assimilado pela firma. Ou seja, se a interação ocorre com universidades, trata-se de uma relação da firma com conhecimento proveniente deste ator e, isso, conforme a literatura, molda a CA da firma. Mas há mais complexidade do que inicialmente se supunha aqui nesta questão. $O$ tipo de conhecimento acessado não necessariamente está diretamente vinculado à sua fonte, ou seja, é razoável supor que as universidades também sejam fonte de conhecimento tecnológico e aplicado ao realizarem serviços de testes e certificações, por exemplo, aproximando-se provavelmente do que é denominado de conhecimento "industrial", proveniente de clientes e fornecedores. Assim, sugere-se que a CA científica e industrial pode ser melhor observada pelo tipo de conhecimento utilizado e não somente pela fonte deste conhecimento, sendo que o tipo de interação que se estabelece com a universidade deve informar melhor a respeito do tipo de conhecimento que é acessado pela firma. 


\section{CONSIDERAÇÕES FINAIS}

Partindo da compreensão de que a firma é um agente que evolui e aprende ao longo do tempo, é fundamental entender os mecanismos de funcionamento deste agente com vistas a identificar elementos determinantes das suas inovações. Entende-se que um caminho interessante para avançar nesta linha é compreender a capacidade que a firma para absorver conhecimento externo. O processo de geração de inovações torna-se cada vez mais complexo e dependente de ativos que extrapolam as fronteiras da firma. Sendo assim, o conceito de "capacidade de absorção" da firma ganha relevância.

Desde a introdução do conceito de CA por Cohen e Levinthal, a literatura apresenta avanços interessantes. Atualmente entende-se que a capacidade de absorção deve ser compreendida como um processo dinâmico e identificada por meio de quatro tipos de esforços da firma: aquisição, assimilação, transformação e exploração de conhecimentos, os quais são classificados em CA Potencial e CA Realizada, ampliando a ideia original de uma relação mais estreita da $\mathrm{CA}$ com a atividade de $\mathrm{P} \& \mathrm{D}$ somente. A literatura atual também aponta para a característica que a capacidade de absorção da firma assume a depender do tipo de conhecimento externo acessado, seja o "científico" ou o "industrial".

O objetivo desse estudo foi, portanto, o de apresentar uma discussão a respeito de métricas utilizadas para medir a CA, bem como uma de estrutura de mensuração da CA de firmas que interagem com Universidades. Para tanto, foram exploradas as contribuições apresentadas na literatura recente, tendo como base Camisón e Forés (2010), JiménezBarrionuevo, et al. (2011) e Flatten, et al. (2011), e proposta uma estrutura de mensuração, considerando os elementos de medição que já haviam sido validados empiricamente nos estudos revisados. A proposta foi validada empiricamente e incluiu um conjunto de sete itens de mensuração para cada uma das quatro dimensões da CA - aquisição, assimilação, transformação e exploração - categorizadas em dois tipos: CA Potencial (aquisição e assimilação) e CA Realizada (transformação e exploração).

Entende-se que o artigo contribui ao propor um conjunto sintético de elementos de mensuração da capacidade absortiva validados empiricamente em firmas que possuíam a especificidade de utilizarem conhecimento externo proveniente das universidades e aponta para a necessidade de continuar avançando em direção à uma proposta mais específica à realidade das firmas que interagem com universidades e à inclusão das dimensões da 
capacidade absortiva científica e industrial na análise da dinâmica inovativa de firmas que interagem com universidades.

\section{REFERÊNCIAS BIBLIOGRÁFICAS}

ABRAMOVSKY, L., et al. Understanding cooperative innovative activity: evidence from four European countries. Economics of Innovation and New Technology forthcoming, 2009.

CAMISÓN, C.; FÓRES, B. Knowledge absorptive capacity: new insights for its conceptualization and measurement. Journal of Business Research , v. 63, n. 7, p. 707-715, Jul. 2010.

CHEN, Chung-Jen. The effects of knowledge attribute, alliance characteristics, and absorptive capacity on knowledge transfer performance. R\&D Management, $\mathrm{V} 34$, Issue 3, pages 311-321, June, 2004.

COHEN, W. M; LEVINTHAL, D. A. Innovation and Learning: the two faces of R\&D. The Economic Journal, 99, p. 569-596, 1989.

. Absorptive-Capacity - a New Perspective on Learning and Innovation. Administrative Science Quarterly, v. 35, n. 1, p. 128-152, 1990.

. Fortune Favors the Prepared Firm. Management Science, v. 40, n. 2, p. 227-251, 1994.

CULLAR, M. J; GALLIVAN, M. J. A framework for ex ante project risk assessment based on absorptive capacity. Elsevier, 173: 1123-1138, 2006.

DYER, JH and SINGH, H. The relational view: cooperative strategy and sources of interorganizational competitive advantage. Acad Manag Rev; 23(4):660-79, 1998.

FLATTEN, T. C, et al. A measure of absorptive capacity: scale development and validation. ESCP Europe, p. 98-116, 2011.

GEORGE, G., S. ZAHRA, et al. The effects of business-university alliances on innovative performance: a study of publicly traded biotechnology companies. Journal of Business Venturing 17(577-609), 2002.

JANSEN, Justin J.P; VAN DEN BOSCH, Frans A.J.; VOLBERDA, Henk W. Managing potential and realized absorptive capacity: how do organizational antecedents matter? Academy of Management Journal, v.48, n.6, p.999-1015, 2005.

JIMÉNEZ-BARRIONUEVO, et al. Validation of an instrument to measure absorptive capacity. Technovation, p. 190-202, 2011.

KIM L. Crisis construction and organizational learning: capability building in catching-up at Hyundai Motor. Organ Sci; 9(4):506-21, 1998.

LANE, P.J.; LUBATKIN, M. Relative absorptive capacity and inter-organizational learning. Strategic Management Journal, 19, 461-477, 1998. 
LANE, P.J.; SALK, J.E.; LYLES, M.A. Absorptive capacity, learning and performance in international joint ventures. Strategic Management Journal, 22, 12, 1139-1161, 2001.

LANE, P.; KOKA, B.; PATHAK, S. The reification of absorptive capacity: a critical review and rejuvenation of the construct. The Academy of Management Review, 31(4):833-863, 2006.

LAURSEN, K.; A.J. SALTER. Searching high and low: what types of firms use universities as a source of innovation?" Research Policy, 33: 1201-1215, 2004.

LINK, A. L; J. REES. Firm size, university based research, and the returns to R\&D. Small Business Economics, 2: 25-31, 1990.

MUROVEC, N.; PRODAN, I. Absorptive capacity, its determinants, and influence on innovation output: cross-cultural validation of the structural model. Technovation, 29(12): 859-872, 2009.

MOWERY, D.C.; OXLEY J.E. Inward technology transfer and competitiveness: the role of national innovation systems. Cambridge Journal of Economy ;19:67-93, 1995.

NEGASSI, S. R\&D co-operation and innovation: a microeconometric study on french firms. Research Policy 33 (3), 365-384, 2004.

NELSON, R.R; ROSENBERG, N. Technical innovation and national systems. In: NELSON R. (Ed.). National innovation systems: a comparative analysis. New York: Oxford University, p. 3-21, 1993.

PLONSKI, G.A. University-industry cooperation: the complex management challenge. Journal Administration, São Paulo, USP, v. 34, n.4, p. 05-12, out/dez 1999.

PÓVOA, L. A Crescente Importância das Universidades e Institutos Públicos de Pesquisa no Processo de Catching-up Tecnológico. Revista de Economia Contemporânea. Rio de Janeiro, v. 12, n.2, p.273-300, maio/agosto de 2008 .

PÓVOA, L.; RAPINI, M. Technology Transfer from Universities and Public Research Institutes to Firms in Brazil: what is transferred and how the transfer is made. XXXVII Encontro Nacional de Economia da ANPEC, Paraná, dezembro, 2009.

SCHMIDT, T. Knowledge flows and R\&D co-operation: firm-level evidence from Germany. ZEW Discussion Paper, 05-22, 2005.

SPENDER, J.C. Industry recipes. Oxford: BasilBlackwell, 1989.

SZULANSKI, G. Exploring internal stickiness: impediments to the transfer of best practice within the firm. Strategic Management Journal, 17, 27-43, 1996.

TORODOVA, G, and DURISIN, B. Absorptive capacity: valuing a reconceptualization. Academy of Management Review, 32(3), 774-786, 2007.

VAN DEN BOSCH, F. A. J.; VAN WIJK, R.V.; VOLBERDA, H.W. Absorptive Capacity: Antecedents, models and outcomes. In: M. Easterby-Smith and M. Lyles (eds) The handbook of organizational learning and knowledge management. Oxford: Blackwell, 2003, p. 278-302. 
VEGA-JURADO, J.; GUTIÉRREZ-GRACIA, A.; FERNÁNDES-de-LUCIO, I. Analyzing the determinants of firm's absorptive capacity: beyond R\&D. R\&D Management, v.38, n.4, p.392-405, 2008.

VERSIANI, A.F, et al. (2010). Mensuração da Capacidade Absortiva: até que ponto a literatura avançou? XXXIV Encontro da Associação Nacional de Programas de PósGraduação em Administração (ANPAD), Rio de Janeiro, 25-29, setembro de 2010.

WAALKENS, J. Innovation in Medium-Sized Architectural and Engineering Firms. Ph.D. Dissertation; Groningen University. Groningen, Netherlands, 2006.

ZAHRA, S. A.; GEORGE, G. Absorptive Capacity: A review, reconceptualization, and extension. Academy of Management Review, v.27, n.2, p.185-203, 2002. 